\title{
Erratum to: Pharmacotherapy in Conjunction with a Diet and Exercise Program for the Treatment of Weight Recidivism or Weight-Loss Plateau Post-Bariatric Surgery: A Retrospective Review
}

Jennifer Schwartz ${ }^{1}$ Umer I. Chaudhry ${ }^{2}$ Andrew Suzo ${ }^{1}$ - Nicholas Durkin ${ }^{1}$. Allison M. Wehr ${ }^{1} \cdot$ Kathy S. Foreman $^{1} \cdot$ Kirsten Tychonievich $^{1}$ - Dean J. Mikami ${ }^{1}$. Bradley J. Needleman ${ }^{1} \cdot$ Sabrena F. Noria ${ }^{1}$

Published online: 4 January 2016

(C) Springer Science+Business Media New York 2016

Erratum to: OBES SURG

DOI 10.10107/s11695-015-1979-x

In the version of this article initially published, the names of authors Umer I. Chaudhry ${ }^{2}$, Kirsten Tychonievich ${ }^{1}$, and Nicholas Durkin ${ }^{1}$ were mistakenly omitted.

The online version of the original article can be found at http://dx.doi.org/ 10.1007/s11695-015-1979-x.

Sabrena F. Noria

sabrena.noria@osumc.edu

1 The Comprehensive Weight Management and Bariatric Surgery Program, Center for Minimally Invasive Surgery, The Ohio State University Wexner Medical Center, Columbus, OH, USA

2 Department of Surgery, Kaiser Permanente Medical Center, San Diego, California, USA 